thyroid-hormone pool. Much emphasis has been placed on the role of the circulating thyroid-hormone binding proteins in regulating the peripheral turnover of thyroid hormones, and the importance of cellular factors has not been adequately stressed. Probably the effect of anticonvulsants on TBG binding is a relatively minor one in patients receiving these drugs. The normal results of the thyroid-hormone binding test indicate that there is no decrease in residual binding sites on TBG, which may result from the occupancy of some sites by the anticonvulsants, a reduction in TBG concentration, or a combination of these factors.

Our detailed analysis of the effects of individual anticonvulsants indicates that phenytoin significantly depresses TT4, FT4, and FT3 concentrations. The other two drugs had no main effects, but with 35 of the 42 patients receiving phenytoin this finding may merely reflect a lack of sufficient data to detect the effects.

Dr P P B Yeo was supported by the Nuffield Foundation, and this work forms part of a dissertation to be submitted to the University of Singapore for the degree of MD. The support of the Scientific and Research Committee of the Newcastle $\operatorname{AHA}(T)$ is gratefully acknowledged.

\author{
References \\ ${ }^{1}$ Oppenheimer, J H, et al, fournal of Clinical Endocrinology and Metabolism, \\ $1961,21,252$.
}

2 Wolff, J, Standaert, M E, and Rall, J E, fournal of Clinical Investigation, $1961,40,1373$

${ }^{3}$ Oppenheimer, J H, and Tavernetti, R R, Endocrinology, 1962, 71, 496.

${ }^{4}$ Lightfoot, R W, jun, and Christian, C L, Fournal of Clinical Endocrinology and Metabolism, 1966, 26, 305.

5 Mendoza, D M, et al, Endocrinology, 1966, 79, 106.

${ }^{6}$ Larsen, P R, et al, fournal of Clinical Investigation, 1970, 49, 1266.

Molholm Hansen, J, et al, fournal of Clinical Endocrinology and Metabolism, 1974, 39, 785.

${ }^{8}$ Liewendahl, K, and Majuri, H, Scandinavian fournal of Clinical and Laboratory Investigation, 1976, 36, 141.

${ }^{9}$ Chin, W, and Schussler, G C, fournal of Clinical Endocrinology and Metabolism, 1968, 28, 181.

10 Cavalieri, R R, Sung, L C, and Becker, C E, fournal of Clinical Endocrinology and Metabolism, 1973, 37, 308.

11 Oppenheimer, J H, Bernstein, G, and Surks, M I, fournal of Clinical Investigation, 1968, 47, 1399.

${ }^{12}$ Cullen, M J, Burger, A G, and Ingbar, S H, V Annual Meeting of European Thyroid Association, Israel, September 1973, p 46 (abstract).

13 Gharib, H, and Munoz, J M, Metabolism, 1974, 23, 515.

${ }_{14}$ Hall, R, Amos, J, and Ormston, B J, British Medical fournal, 1971, 1, 582.

${ }_{15}$ Hesch, R D, and Evered, D C, British Medical fournal, 1973, 1, 645.

16 Evered, D C, et al, fournal of Clinical Pathology, 1976, 29, 1054.

17 Ratcliffe, W A, Marshall, J, and Ratcliffe, J G, Clinical Endocrinology, 1976, 5, 631 .

18 Yeo, P P B, Lewis, M, and Evered, D C, Clinical Endocrinology, 1977, 6, 159.

19 Toseland, P A, Grove, J, and Berry, D J, Clinica Chimica Acta, 1972, 38, 321.

2" Nelder, J A, General Linear Interactive Modelling. London, Numerical Algorithms Group, RSS, 1975.

21 Yeo, P P B, et al, fournal of Endocrinology, 1977, 73, 45

\title{
High incidence of a concentration-dependent skin reaction in children treated with phenytoin
}

\author{
J T WILSON, B HÖJER, G TOMSON, A RANE, F SJÖQVIST
}

British Medical fournal, 1978, 1, 1583-1586

\section{Summary and conclusions}

A particularly high incidence of rash was seen in children with epilepsy treated with phenytoin. Ten children with untreated epilepsy were therefore included in a prospective study and given either 3 (group 1) or 6 (group 2) $\mathrm{mg}$ of phenytoin $/ \mathrm{kg}$ body weight/day for five days followed by $6 \mathrm{mg} / \mathrm{kg}$ body weight/day for both groups. Four of the five children in group 2 compared with only one of the five in group 1 developed a rash seven to 12 days after the start of treatment. Patients with rashes had significantly higher plasma phenytoin concentrations. Whenever the phenytoin concentration was higher than $14 \mu \mathrm{mol} / 1$ on day 5 a rash occurred.

These findings indicate that the generalised skin reaction is caused by a high body burden of phenytoin, which results from either a high load of the drug or a low clearance rate.

Departments of Clinical Pharmacology and Paediatrics, Karolinska Institute, Huddinge University Hospital, S-141 86 Huddinge, Sweden

J T WILSON, MD, professor of paediatrics and pharmacology (present address: Division of Paediatric Clinical Pharmacology, Vanderbilt University Medical Centre, Nashville, USA)

B HÖJER, MD, lecturer in paediatrics

G TOMSON, MD, registrar in paediatrics

A RANE, MD, associate professor in clinical pharmacology

F SJÖQVIST, MD, professor of clinical pharmacology

\section{Introduction}

About $5^{\circ}{ }^{\circ}$ of children treated with phenytoin develop a mild transient maculopapular rash, usually within two weeks of the start of treatment. ${ }^{1}=$ Adverse systemic effects do occur after phenytoin but are less common than the skin reaction. ${ }^{3-6} \mathrm{~A}$ severe exanthem ${ }^{7}$ and blood dyscrasia ${ }^{8}$ have been seen in patients with therapeutic or exceptionally high plasma phenytoin concentrations. The nature of such reactions (allergic or toxic) is obscure. Unfortunately in most patients presenting with a rash plasma concentrations of phenytoin and its metabolites have not been measured. An assessment of the amount of drug in the body at different times after the start of treatment and at the time of an exanthem is needed to elucidate the mechanisms responsible for the skin reaction.

In a study ${ }^{9}$ on the plasma profile of phenytoin and its phydroxylated metabolite in children who received loading or conventional doses of the drug we encountered an unexpectedly high incidence of rash ( 8 out of 13 children developed a rash). We therefore performed a prospective study using two regimens of phenytoin to determine the incidence of rash and its relation to the kinetics of phenytoin.

\section{Patients and methods}

All epileptic children who presented in the paediatric clinic of Huddinge Hospital in Stockholm and were treated with phenytoin were recruited into the study. The children and their parents were told about the possibility of a rash after phenytoin treatment, and the study was approved by the Huddinge Hospital ethical committee.

Ten children (five boys and five girls aged 6-15 years), all untreated 
epileptics, were randomly assigned to two treatment groups (five children in each). Medical history was reviewed and a clinical examination performed at the start of treatment and on days $3,6,9$, 14 , and 21 of treatment. The children were examined in the nude; if a rash occurred it was documented with a photograph,* and phenytoin was discontinued and subsequently restarted at a lower dose in all patients except one. This child was treated continuously despite the development of a rash, which disappeared spontaneously.

\section{DRUG REGIMENS}

In our previous study ${ }^{9}$ we used four preparations of phenytoin, two of which contained dyes (tartrazine, erythrosine, and indigo carmine). Some dyes are known to have allergenic potential, ${ }^{10}$ so all patients in this study were treated with sodium phenytoin substance as provided by Parke-Davis (Epanutin (Dilantin in USA)). A bodyweight adjusted dose $(\mathrm{mg} / \mathrm{kg})$ was prepared for each patient and then mixed with lactose. The preparation was administered in plain gelatin capsules. To achieve different plasma concentrations of phenytoin children in group 1 were given $3 \mathrm{mg} / \mathrm{kg}$ body weight/day for five days and then $6 \mathrm{mg} / \mathrm{kg} / \mathrm{day}$, and children in group 2 were given $6 \mathrm{mg} / \mathrm{kg} / \mathrm{day}$ (conventional dose) from the start of treatment.

\section{ANALYSES}

Plasma samples were collected before the morning dose on the first day of treatment and then on days $6,9,14$, and 21 . For the phenytoin analyses blood samples were collected in heparinised tubes and plasma was separated and frozen if not analysed immediately.

Routine analysis of phenytoin alone was performed by gas-liquid chromatography ${ }^{11}$ after extraction from plasma. ${ }^{12}$ The binding of phenytoin to plasma proteins was measured by an equilibrium dialysis technique according to Ehrnebo et al. ${ }^{13}$

Other laboratory values measured included haemoglobin, packed cell volume, white blood cell count, total eosinophil count, alanine and aspartate aminotransferases, IgE, and erythrocyte sedimentation rate. These analyses were carried out before the start of treatment and on the ninth and 21st days of treatment and within two days of the onset of a rash. Routine clinical laboratory methods were used. Serological analyses for antibodies against rubella, measles, adenovirus, and other viruses were performed in all children who developed a rash. Plasma drawn before the onset of the rash and at least three weeks later was used for serological studies.

Statistical methods-Routine statistical methods were used. To test the significance of differences of mean concentrations a two-way (with respect to time and group) analysis of variance was used.

\section{Results}

The highest incidence of rash was found among the children given conventional doses of phenytoin: four children in group 2 compared with one in group 1 developed a rash. The rash invariably appeared seven to 12 days after the start of treatment. It usually began on the medial side of the thighs and spread to the rest of the limbs or the trunk or both (see figure). Only in one patient did the rash first appear on the lumbar region and then spread to the trunk. Mucous membranes were not affected. The rash was polymorphic and usually mild; in one case it was so mild that it was not noticed until the child came for examination. Only one child had associated pruritus.

The exanthem lasted for three to five days after treatment was discontinued, and after it had subsided phenytoin was readministered in a dose of $1.5 \mathrm{mg} / \mathrm{kg} /$ day with increases of $1.5 \mathrm{mg} / \mathrm{kg} /$ day every three days. In no case did the skin reaction reappear. In one patient the initial treatment was continued despite the appearance of a skin

*Available from the authors on request.

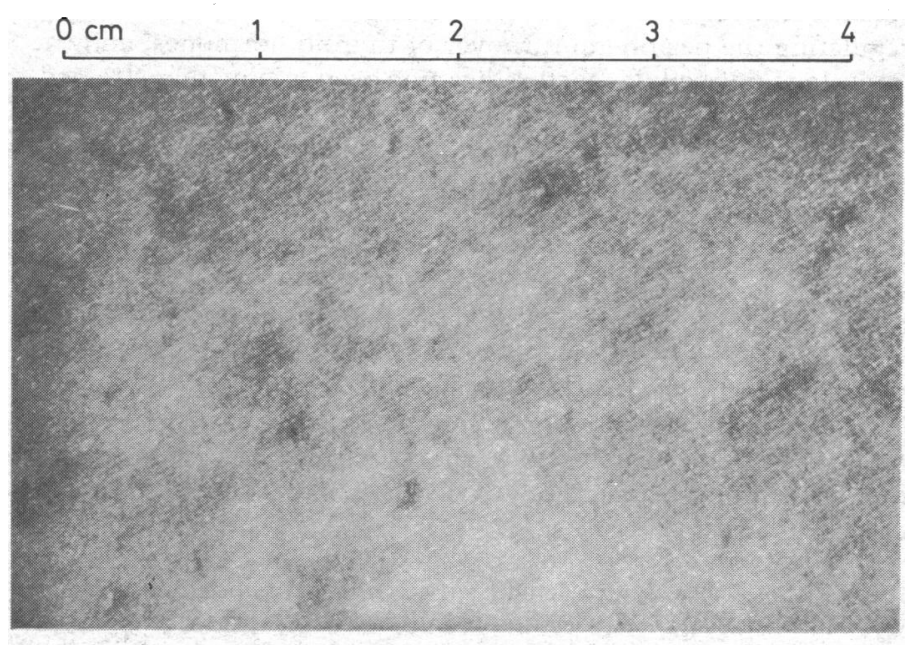

Appearance of rash in 10-year-old boy who received regimen 2. Top: closeup appearance of rash on abdomen. Bottom: front of thighs.

reaction, because a viral infection was suspected (because of a false report about exanthematous disease in the neighbourhood and enlargement of lymph nodes in the patient). This rash disappeared with continued treatment.

Table I shows the mean plasma concentrations of phenytoin during treatment. The difference between children with a rash and those without was significant $(P=0.05)$ when tested by a two-way analysis of variance and also when tested on each day with Wilcoxon's rank order test. There was almost no overlap in plasma phenytoin concentration between the two groups (table II). The data indicated that a concentration of about $14 \mu \mathrm{mol} / 1(3.5 \mu \mathrm{g} / \mathrm{ml})$ on days 3 and 6 was critical for a rash to occur. The average ratio of plasma phenytoin concentration to the weight-adjusted daily dose of phenytoin was significantly higher on days 3,6 , and 9 in the children who developed a rash (table I); but the mean plasma protein binding of phenytoin in the children with rash was similar to that in the children with no

TABLE I-Mean $( \pm S D)$ plasma concentration of phenytoin and ratio of concentration to dose in children with and without rash

\begin{tabular}{|c|c|c|c|c|c|c|}
\hline \multirow[b]{2}{*}{ Day: } & \multicolumn{3}{|c|}{ Plasma phenytoin $(\mu \mathrm{mol} / \mathrm{l})$} & \multicolumn{3}{|c|}{ Concentration: dose } \\
\hline & 3 & 6 & 9 & 3 & 6 & 9 \\
\hline $\begin{array}{l}\text { Children with rash } \\
\text { Children without rash }\end{array}$ & $\begin{array}{r}21 \cdot 4 \pm 7 \cdot 8 \\
6.6 \pm 6 \cdot 3\end{array}$ & $\begin{array}{c}28 \cdot 2 \pm 11 \cdot 4 \\
7 \cdot 8 \pm 6 \cdot 0\end{array}$ & $\begin{array}{l}34 \cdot 8 \pm 15 \cdot 3 \\
14 \cdot 4 \pm 8 \cdot 7\end{array}$ & $\begin{array}{l}4 \cdot 0 \pm 1 \cdot 0 \\
1 \cdot 7 \pm 1 \cdot 6\end{array}$ & $\begin{array}{l}4 \cdot 7 \pm 1 \cdot 9 \\
1 \cdot 3 \pm 1 \cdot 0\end{array}$ & $\begin{array}{l}5 \cdot 8 \pm 2 \cdot 6 \\
2 \cdot 4 \pm 1 \cdot 5\end{array}$ \\
\hline
\end{tabular}


TABLE II-Plasma concentrations ( $\mu$ mol $/ l$ ) of phenytoin in the 10 children

\begin{tabular}{|c|c|c|c|c|c|}
\hline \multirow{2}{*}{$\begin{array}{l}\text { Case } \\
\text { No }\end{array}$} & \multirow{2}{*}{ Rash } & \multicolumn{4}{|c|}{ Phenytoin $(\mu \mathrm{mol} / \mathrm{l})$} \\
\hline & & Day 3 & Day 6 & Day 9 & $\begin{array}{l}\text { Within two days of } \\
\text { rash appearing (day No) }\end{array}$ \\
\hline $\begin{array}{r}1 \\
2 \\
3 \\
4 \\
5 \\
6 \\
7 \\
8 \\
9 \\
10\end{array}$ & $\begin{array}{l}+ \\
+ \\
+ \\
+ \\
- \\
\pm \\
- \\
= \\
-\end{array}$ & $\begin{array}{l}33 \\
24 \\
21 \\
16 \\
14 \\
13 \\
13 \\
<4 \\
<4 \\
<4\end{array}$ & $\begin{array}{r}44 \\
32 \\
30 \\
21 \\
14 \\
14 \\
14 \\
7 \\
<4 \\
<4\end{array}$ & $\begin{array}{l}60 \\
37 \\
31 \\
22 \\
15 \\
24 \\
26 \\
12 \\
17 \\
<4\end{array}$ & $\begin{array}{l}52(10) \\
37(9) \\
40(13) \\
19(14) \\
31(14)\end{array}$ \\
\hline
\end{tabular}

rash $(86.3 \pm 0.5 \%$ and $86.3 \pm 0.4 \%$ respectively). Retrospective evaluation of the average ratio of plasma $\mathrm{p}$-hydroxyphenytoin to phenytoin in children with and without a rash in our previous study ${ }^{9}$ showed that children with a rash consistently had a lower ratio than children without a rash (table III).

The design of the study excluded the possibility that the rash was a hypersensitivity reaction to drug additives. We found no evidence of reagin-mediated type I hypersensitivity reaction, since no patients showed a rise in eosinophil count or in $\operatorname{IgE}$ concentration. Furthermore, it was possible to restart treatment with phenytoin slowly only two days after the rash had disappeared. Negative results of serological studies ruled out a concurrent viral illness in those with a rash.

\section{Discussion}

A skin reaction to phenytoin has been reported in about $5 \%$ of epileptic children ${ }^{1214}$; it seems to be more common in children $^{1}{ }^{74-18}$ than in adults. $^{35} \mathrm{~A}$ mild maculopapular erythema or erythema multiforme is typically described, but serious reactions of Stevens-Johnson type have also been reported. ${ }^{6}{ }^{716-18}$ The prevalence of serious or fatal reactions among reported cases undoubtedly overemphasises the serious exanthem, while the actual prevalence of a mild to moderate rash is underestimated, possibly because patients do not report the rashes to their doctors.

Including the children in our prospective study, reported here, we have seen rashes develop in $15(54 \%)$ out of 28 children treated with phenytoin-the highest incidence yet reported. The other cases of rash occurred among children treated before and after the present study. Eight of the 13 children treated in a previous study ${ }^{9}$ with different initial regimens of phenytoin developed a rash, as did two out of five children treated after the end of the present study. These last five children were all treated by the low-dose regimen (that given to group 1), but plasma concentrations in the two who developed a rash reached over $14 \mu \mathrm{mol} / 1$ on days 3 and 6 of treatment.

The possibility that a contaminant of Epanutin was responsible for the rash seems remote, since we found the same reaction with other preparations of phenytoin. ${ }^{9}$ Our results therefore show clearly a relation between the plasma concentration of phenytoin and the occurrence of a rash seven to 12 days after the start of treatment in previously untreated children. Although only a few patients were studied, a plasma concentration above $14 \mu \mathrm{mol} / 1$ on days 3 and 6 seemed to predict fairly accurately the occurrence of a skin reaction.

About $100 \%$ of the phenytoin sodium in Epanutin is absorbed, ${ }^{19}$ and therefore the differences in plasma concentration cannot be explained by individual differences in absorption.
Furthermore, the plasma protein binding of phenytoin did not differ between those with and without a rash. Differences in plasma concentrations thus depended on the dose received and on the metabolic clearance of the drug in each patient. An analysis of data from our previous study ${ }^{9}$ showed that the ratio of plasma concentrations of total p-hydroxyphenytoin to those of phenytoin were consistently higher in patients without a rash than in patients with a rash (table III). Although these data were collected retrospectively they indicate that patients with a rash had a lower capacity for metabolising phenytoin to p-hydroxyphenytoin than did patients without a rash. A higher degree of saturation by phenytoin of the drug metabolising enzymes ${ }^{20}$ might explain higher plasma concentrations of phenytoin and a lower ratio of p-hydroxyphenytoin: phenytoin in those with a rash. A phenytoin concentrationdependent rash is thus evident, but the role of phenytoin and its metabolites remains unknown. A slow rate of para-hydroxylation might, however, produce increased metabolism via other pathways.

Covalent binding of intermediate metabolites of some drugs may produce liver necrosis which is predominantly centrilobular. ${ }^{21}$ For most drugs tested covalent binding was a function of dose or body burden of the drug. Examination of histological findings in cases of phenytoin-associated liver toxicity ${ }^{4} 152223$ has shown that several patients had a centrilobular necrosis. The possibility of a similar toxic reaction occurring in the skin of children must be considered in view of the relation of the rash to dose and to plasma concentrations of phenytoin. Part of phenytoin is in fact metabolised via an epoxide pathway, as shown by the finding of dihydrodiol metabolites of phenytoin in human urine. ${ }^{24}$ Formation of a reactive metabolite by the skin shortly after the start of phenytoin treatment would place the skin at risk from toxic effects.

The surprisingly high incidence of rash in our patients might be explained by the fact that we used only drugs with complete bioavailability and gave them to untreated children. In Sweden the use of a phenytoin preparation (Difhydan) with incomplete bioavailability has been predominant, while in the USA phenytoin has usually not been the first drug used to treat seizure disorders in children. Previous treatment with other anticonvulsants such as phenobarbitone may have induced the metabolism of phenytoin or a toxic metabolite and thus precluded a high prevalence of rash.

Whatever the mechanism producing the rash, conventional doses of phenytoin with complete bioavailability should not be given to untreated children unless the need for immediate treatment of seizures or other conditions outweighs the discomfort of a skin reaction.

We thank Ulf Brodin for valuable advice on the statistical aspects of this study. This work was supported by a grant from the Swedish Medical Research Council (No 04X-04496). JTW is the recipient of a Research Career Development Award from the National Institutes of Health (K4-HD42,539).

\section{References}

${ }^{1}$ Livingstone, S, Postgraduate Medicine, 1956, 20, 584.

${ }^{2}$ Merritt, H H, and Putnam, T J, American fournal of Psychiatry, 1940 96, 1023.

${ }^{3}$ Chaiken, B H, Goldberg, B I, and Segal, J P, New England fournal of Medicine, 1950, 242, 897.

${ }_{4}^{4}$ Dhar, C J, et al, Postgraduate Medicine, 1974, 56, 128.

5 Gropper, A L, New England fournal of Medicine, 1956, 254, 522.

TABLE III-Mean $( \pm S D)$ ratio of plasma p-hydroxyphenytoin to plasma phen

\begin{tabular}{l|c|c|c|c|c|c|}
\hline \multicolumn{1}{c|}{ Day: } & 1 & 2 & 3 \\
\hline $\begin{array}{l}\text { Children with rash } \\
\text { Children without rash }\end{array}$ & $\begin{array}{c}0 \cdot 24 \pm 0 \cdot 12(4) \\
0.31(1)\end{array}$ & $\begin{array}{c}0 \cdot 16 \pm 0 \cdot 05(4) \\
0 \cdot 22(1)\end{array}$ & $\begin{array}{c}0 \cdot 16 \pm 0 \cdot 045(2) \\
0 \cdot 26(5)\end{array}$ & $\begin{array}{c}0 \cdot 17 \pm 0 \cdot 026(8) \\
0 \cdot 21 \pm 0 \cdot 054(4)\end{array}$ \\
\hline
\end{tabular}


${ }^{6}$ Robinson, H M, jun, and Stone, J H, Archives of Dermatology, 1970, 101, 462.

7 Dawson, K P, Archives of Disease in Childhood, 1973, 48, 239.

${ }^{8}$ Parker, W A, and Gumnit, R J, Neurology, 1974, 24, 1178.

${ }^{2}$ Wilson, J T, Höjer, B, and Rane, A, Clinical Pharmacology and Therapeutics, 1976, 20, 48.

10 Juhlin, L, Michaëlsson, G, and Zetterström, O, fournal of Allergy and Clinical Immunology, 1972, 50, 92.

11 Berlin, A, et al, Scandinavian fournal of Clinical and Laboratory Investigation, 1972, 29, 281.

12 Mac Gee, J, Annals of Chemistry, 1970, 42, 421.

13 Ehrnebo, M, et al, European fournal of Clinical Pharmacology, 1971, 3, 189.

14 Norell, E, Liljenberg, G, and Gamstorp, I, European fournal of Neurology, $1975,13,232$.

${ }^{15}$ Chien, L T, Ceballos, R, and Benton, J W, jun, Alabama fournal of Medical Sciences, 1970, 7, 318.
${ }^{16}$ Greenberg, L M, et al, Annals of Ophthalmology, 1971, 3, 137.

${ }^{17}$ Heller, G, and Sloane, M, Pediatrics, 1950, 5, 836.

18 Watts, J C, Pediatrics, 1962, 30, 592.

${ }^{19}$ Lund, L, European fournal of Clinical Pharmacology, 1974, 7, 119.

20 Gerber, N, Lynn, R, and Oates, J, Annals of Internal Medicine, 1972, 77, سִ 765.

${ }^{21}$ Mitchell, J R, and Jollows, D J, Gastroenterology, 1975, 68, 392.

22 Crawford, T B B, Nisbet, H B, and Ritchie, D, Fournal of Pharmacy and Pharmacology, 1952, 4, 294.

${ }^{23}$ Duma, R J, Hendry, C N, and Donohoo, J S, Southern Medical Fournal, 1966, 59, 168.

${ }^{24}$ Horning, M G, et al, Placental Transfer of Drugs, Fetal Pharmacology, ed L O Boréus. New York, Raven Press, 1973.

\title{
Effect of paracetamol on gastric mucosa
}

\author{
KEVIN J IVEY, G R SILVOSO, WILLIAM J KRAUSE
}

British Medical fournal, 1978, 1, 1586-1588

\section{Summary and conclusions}

The effect of paracetamol on the gastric mucosa was examined in seven healthy volunteers. The dose used ( $2 \mathrm{~g}$ instilled in $100 \mathrm{ml}$ isotonic saline) was equivalent to about six tablets taken with water. Biopsy specimens were taken before and 10 and 60 minutes after instillation. The mean incidence of damaged surface cells in the control period was $1.7 \%$. Ten minutes after instillation $3.5 \%$ of the surface cells were damaged. This increase was not significant. Light microscopy showed focal cell disruption and infiltration of red blood cells. Scanning electronmicroscopy showed minimal loss of normal cell apices. No erosions were seen on microscopy. Biopsy specimens taken 60 minutes after paracetamol showed similar changes.

These findings differ appreciably from the extensive cell damage and microscopic erosions caused by therapeutic doses of $600 \mathrm{mg}$ (two tablets) of aspirin. We conclude that large "analgesic" doses of paracetamol cause minimal ultrastructural changes in normal human gastric mucosa. The continued use of paracetamol in place of aspirin appears to be justified when there is a possibility of gastric mucosal injury.

\section{Introduction}

Paracetamol (acetaminophen (USA)) is commonly used as a substitute for aspirin. Data based on the retail sales of analgesics in pharmacies and on prescriptions in the UK indicate that sales of paracetamol increased from $70 \%$ of aspirin sales in 1965 to $150 \%$ in $1971 .{ }^{1}$ Paracetamol and aspirin have similar analgesic and antipyretic properties. ${ }^{2}$ Nevertheless, confusion has arisen as a result of recent advertising by some aspirin manufacturers, in which the report ${ }^{3}$ of the United States Food and Drug

\footnotetext{
Departments of Medicine and Anatomy, Harry S Truman Memorial Veterans Hospital and University of Missouri Medical Centre, Columbia, Missouri

KEVIN J IVEY, MRCP, FACP, associate professor of medicine G R SILVOSO, MD, fellow in gastroenterology

WILLIAM J KRAUSE, PHD, associate professor of anatomy
}

Administration was quoted to the effect that paracetamol was 0 no safer than aspirin. The report-though not the advertisements-made it clear that this was because of the hepatotoxicity $\vec{v}$ of paracetamol. Nevertheless, because of the hepatotoxicity this seemed to be an appropriate time to re-examine the effects of $\overparen{\Phi}$ the drug on the stomach.

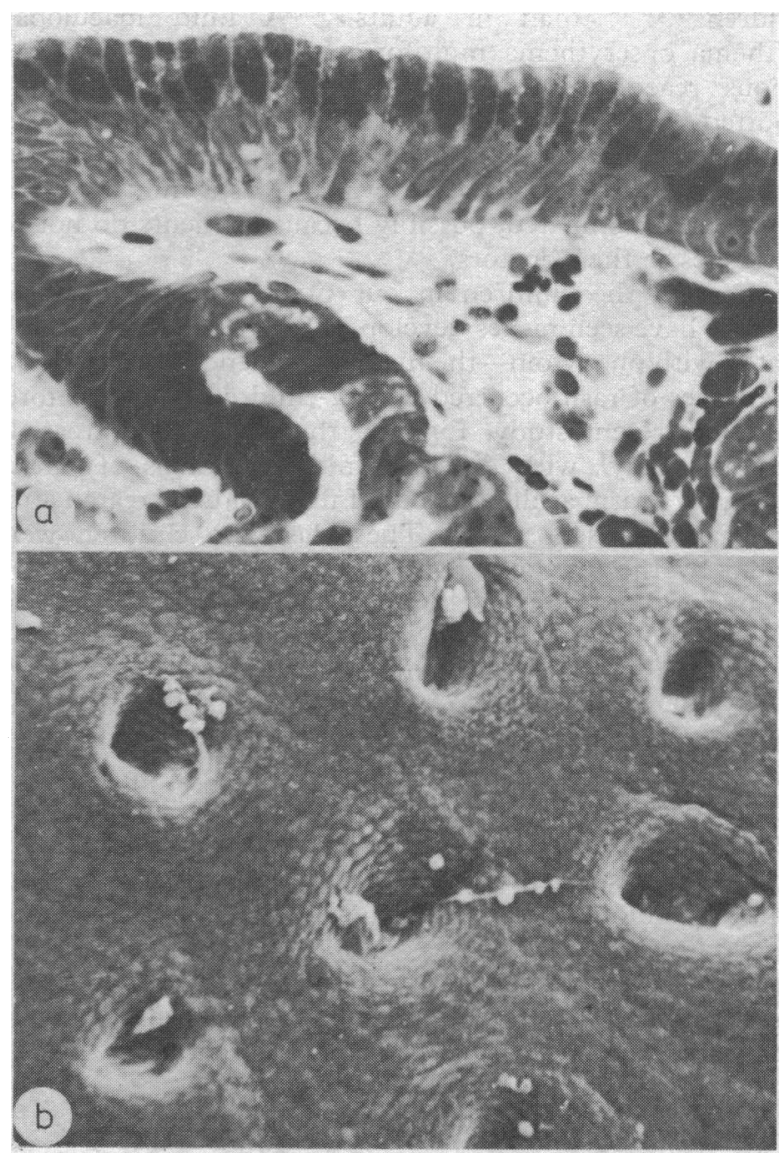

FIG 1-(a) Section of normal gastric mucosa from fundus seen by light microscopy. Mucosal surface is intact. (Epon 812 section (Fisher Scientific Co, Fairlawn, New Jersey); toluidine blue. Original magnification: $\times 400$.) $(b)$ Normal gastric mucosa as viewed from mucosal surface by scanning electron microscopy. Foveolae are evident as well as individual cell apices, giving surface a cobblestone appearance. (Original magnification: $\times$ 400.) 